\title{
Preparation and Characterization of Molecular Sieving Carbon by Methane and Benzene Cracking over Activated Carbon Spheres
}

\author{
Harish Chandra Joshi^, Rajesh Kumar, Rohitashaw Kumar Singh and Darshan Lal \\ Defence Materials and Stores Research \& Development Establishment, G.T Road, Kanpur-208013, India \\ ‘e-mail: joshi.hari@gmail.com \\ (Received February 4, 2007; Accepted March 7, 2007)
}

\begin{abstract}
Molecular sieving carbon (MSC) for separating $\mathrm{O}_{2}-\mathrm{N}_{2}$ and $\mathrm{CO}_{2}-\mathrm{CH}_{4}$ has been prepared through chemical vapor deposition (CVD) of methane and benzene on activated carbon spheres (ACS) derived from polystyrene sulfonate beads. The validity of the material for assessment of molecular sieving behavior for $\mathrm{O}_{2}-\mathrm{N}_{2}$ and $\mathrm{CO}_{2}-\mathrm{CH}_{4}$ pair of gases was assessed by the kinetic adsorption of the corresponding gases at $25^{\circ} \mathrm{C}$. It was observed that methane cracking on ACS lead to deposition of carbon mostly in whole length of pores rather than in pore entrance, resulting in a reduction in adsorption capacity. MSC showing good selectivity for $\mathrm{CO}_{2}-\mathrm{CH}_{4}$ and $\mathrm{O}_{2}-\mathrm{N}_{2}$ separation was obtained through benzene cracking on ACS with benzene entrantment of $0.40 \times 10^{-4} \mathrm{~g} / \mathrm{ml}$ at cracking temperature of $725^{\circ} \mathrm{C}$ for a period of 90 minutes resulting in a selectivity of $3.31: 1.00$ for $\mathrm{O}_{2}-\mathrm{N}_{2}$ and 8.00:1.00 for $\mathrm{CO}_{2}-\mathrm{CH}_{4}$ pair of gases respectively.
\end{abstract}

Keywords : Molecular sieving carbon, Adsorption kinetics, Chemical vapor deposition, Activated carbon spheres

\section{Introduction}

The separation based on carbon molecular sieves (CMS) is getting popularity owing to its selectivity at molecular level and its hydrophobic character. In the recent past, a large number of separation processes based on CMS have been commercialized [1-8]. Due to wide range of pore size distribution $(5-20,000 \AA)$, activated carbons find limited applications in separation of gases. CMS on the other hand are able to separate gas mixtures of industrial interest owing to narrow pore size distribution. An effective CMS is defined by two properties viz., selectivity for the adsorption of one of the species in the gas mixtures to be separated, followed by high adsorption capacity for the same. Bearing these two conditions in mind, MSC or CMS has been prepared from different starting materials through a variety of processes ranging from controlled pyrolysis or activation of polymers $[2,3]$ to modification of texture of porous or activated carbon through CVD of organic substances [3-6]. The CVD method for CMS synthesis has attracted much interest as it allows better optimization of adsorption capacity and selectivity for the separating species separately. Adsorption capacity is developed during the production of activated carbon while selectivity is introduced by creation of constrictions in the entrances of pores by carbon deposition at the pore entrances during hydrocarbon cracking process. In a broad sense MSC is micro porous carbon whose special textural characteristics enable kinetic separation of gas mixtures i.e. separation as a result of differences in the diffusion rates of the species to be separated.

Benzene is one of the organic substances that has been mostly employed for carbon deposition in activated carbon containing wide pores $[4,8]$. Methane is another non-toxic, abundant and cheap substance which is also a promising candidate to be used as cracking agent for carbon deposition. In the present investigation ACS obtained from polymeric precursor polystyrene sulfonate were chosen as a starting material to prepare MSC. The porosity of the base material was altered by carbon deposition through cracking of benzene and methane. The process resulted in narrowing of the pores in the base material, which led to molecular sieving behavior in ACS.

\section{Experimental}

\subsection{Materials}

ACS obtained by carbonization and activation of polystyrene sulfonate beads were chosen as a starting material for preparation of MSC. Polystyrene sulfonate beads were supplied by M/s Ion Exchange Resin, Mumbai, India. AR grade benzene was procured from Ranbaxy Laboratories Ltd, India. $\mathrm{O}_{2}, \mathrm{~N}_{2}, \mathrm{CO}_{2}$, and $\mathrm{CH}_{4}$ all AR grade were supplied by Indian Oxygen Limited (IOL), India with a minimum purity of $99.99 \%$.

\subsection{Methods}


Carbon deposition experiments were carried out in a tubular quartz reactor (length $750 \mathrm{~mm}, 30 \mathrm{~mm} \mathrm{ID}$ ) containing 5.0 grams of ACS on a static silica bed. The reactor was placed vertically in an electric furnace and then the furnace was heated to the desired temperature. A temperature indicator connected to a precalibrated chromel -alumel thermocouple performed the temperature control. For benzene cracking a controlled flow of nitrogen was maintained through the benzene reservoir. Nitrogen gas saturated with benzene vapors was passed through the reactor for cracking on ACS. In case of methane, pure gas stream was passed through the reactor for cracking. The samples were prepared keeping benzene and methane concentration constant and varying cracking duration. The abbreviation used for samples exposed to methane cracking for different periods of time is referred as $\mathrm{CSM}_{\mathrm{t}}$ where CSM will specify carbon spheres subjected to methane cracking and $t$ will specify cracking duration for example, $\mathrm{CSM}_{120}$ denotes activated carbon sphere sample exposed to methane cracking for 120 minutes. Similarly carbon sphere samples exposed to the action of benzene are given by $\mathrm{CSB}_{\mathrm{t}}$. Thus, sample $\mathrm{CSB}_{90}$ signifies benzene cracked carbon sphere sample for a duration of 90 minutes. The prepared samples were analyzed for the selective adsorption of $\mathrm{O}_{2}$ versus $\mathrm{N}_{2}$ and $\mathrm{CH}_{4}$ versus $\mathrm{CO}_{2}$ at $25^{\circ} \mathrm{C}$.

\subsection{Characterization}

Adsorption and molecular sieving properties of ACS were evaluated at $25^{\circ} \mathrm{C}$ by volumetric adsorption of gases like $\mathrm{O}_{2}$, $\mathrm{N}_{2}, \mathrm{CO}_{2}$, and $\mathrm{CH}_{4}$ on neat ACS and on ACS subjected to either methane or benzene cracking separately. All the samples were taken in a glass burette and thoroughly degassed at 300 ${ }^{\circ} \mathrm{C}$ for a period of six hours in vacuum of the order of $10^{-4}$ torr before proceeding for adsorption measurement experiments. Volume of the gas taken up by the sample in a particular time interval was determined by change in pressure in a closed system. Several authors making use of various volumetric systems have followed this method $[5,6]$. The decrease in differential pressure due to gaseous adsorption was recorded and the amount adsorbed in a given time interval was calculated. All the uptake experiments were repeated more than three times, and the error in the measurements was less than $1 \%$. The amount adsorbed was plotted against time to get a kinetic uptake curve. From the kinetic curves uptake ratio of gases with time were calculated. Ratio of amounts of gases adsorbed after 60 seconds was used to assess the performance behavior of the material as MSC.

As mentioned in the experimental section 2.1, ACS were prepared in the laboratory by carbonization of polystyrene resin beads followed by physical activation in $\mathrm{CO}_{2}$ atmosphere at $850^{\circ} \mathrm{C}$ for a period of twelve hours. Neat activated carbon sphere sample i.e. ACS and ACS subjected to benzene cracking for 90 minutes (sample- $\mathrm{CSB}_{90}$ ) were characterized for BET surface area, micropore volume and total
Table 1. Parameters of pore structure for neat ACS and ACS subjected to benzene cracking for a duration of 90 minutes $\left(\right.$ Sample $\left.\mathrm{CSB}_{90}\right)$

\begin{tabular}{lcc}
\hline \multicolumn{1}{c}{ Parameter } & ACS & $\begin{array}{c}\text { Benzene cracked } \\
\text { ACS }\left(\mathrm{CSB}_{90}\right)\end{array}$ \\
\hline Total pore volume $\left(\mathrm{cm}^{3} / \mathrm{g}\right)$ & 0.67 & 0.48 \\
Micropore volume $\left(\mathrm{cm}^{3} / \mathrm{g}\right)$ & 0.37 & 0.10 \\
Mesopore volume $(\%)$ & 44.7 & 79 \\
BET surface area $\left(\mathrm{m}^{2} / \mathrm{g}\right)$ & 856 & 288
\end{tabular}

*ACS prepared by carbonization and activation of polystyrene sulfonate beads at $850^{\circ} \mathrm{C}$ for a duration of twelve hours

pore volume from nitrogen adsorption isotherm at $-196^{\circ} \mathrm{C}$, using Thermofinnigan make surface area analyzer Sorptomatic 1990. Micropore volume has been determined using Dubinin \& Radushkevich (DR) equation. Total pore volume has been determined from nitrogen adsorption isotherm by measuring nitrogen volume adsorbed at a relative pressure of 0.95 and further converting it into liquid volume considering density of nitrogen as $0.808 \mathrm{cc} / \mathrm{g}$ in liquid state. Mesopore volume was evaluated by subtracting micropore volume from total pore volume. Table 1 includes the pore structure characteristics corresponding to original $\mathrm{ACS}$ and sample $\mathrm{CSB}_{90}$.

\section{Results and Discussion}

\subsection{Adsorption kinetics of Nitrogen $\left(\mathrm{N}_{2}\right)$, Oxygen $\left(\mathrm{O}_{2}\right)$, Meth- ane $\left(\mathrm{CH}_{4}\right)$ and Carbon dioxide $\left(\mathrm{CO}_{2}\right)$ on $\mathrm{ACS}$ and $\mathrm{ACS}$ subjected to methane cracking}

The volume uptake results for $\mathrm{O}_{2}-\mathrm{N}_{2}$ and $\mathrm{CO}_{2}-\mathrm{CH}_{4}$ pair of gases for ACS as well as ACS subjected to methane cracking for different time duration are summarized in Table 2. Sample $\mathrm{CSM}_{120}$ has been chosen as a representative sample for which uptake curves are shown in Figs. 1 \& 2 respec-

Table 2. Uptake ratio of $\mathrm{O}_{2}-\mathrm{N}_{2}$ and $\mathrm{CO}_{2}-\mathrm{CH}_{4}$ on neat ACS and ACS subjected to methane cracking for different cracking duration

\begin{tabular}{lccc}
\hline Sample & $\begin{array}{c}\text { Cracking } \\
\text { Time } \\
\text { (minutes) }\end{array}$ & $\begin{array}{c}\text { Uptake ratio of } \\
\mathrm{O}_{2}: \mathrm{N}_{2} \text { at } \\
60 \text { seconds }\end{array}$ & $\begin{array}{c}\text { Uptake ratio of } \\
\mathrm{CO}_{2}: \mathrm{CH}_{4} \text { at } \\
60 \text { seconds }\end{array}$ \\
\hline $\mathrm{ACS}^{*}$ & 0 & $0.47: 1.00$ & $1.42: 1.00$ \\
$\mathrm{CSM}_{30}$ & 30 & $2.00: 1.00$ & $1.52: 1.00$ \\
$\mathrm{CSM}_{120}$ & 120 & $2.33: 1.00$ & $2.90: 1.00$ \\
$\mathrm{CSM}_{150}$ & 150 & $3.00: 1.00$ & $3.50: 1.00$ \\
$\mathrm{CSM}_{180}$ & 180 & $2.75: 1.00$ & $3.10: 1.00$ \\
\hline
\end{tabular}

(Methane cracking temperature $850^{\circ} \mathrm{C} \&$ methane entrainment 6.50 $\times 10^{-4} \mathrm{~g} / \mathrm{ml}$ )

*ACS prepared by carbonization and activation of polystyrene sulfonate beads at $850^{\circ} \mathrm{C}$ for a duration of twelve hours. 


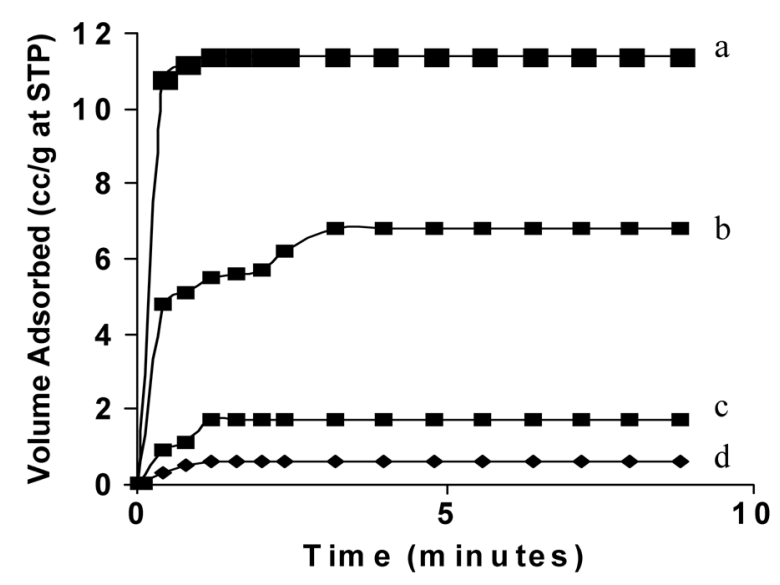

Fig. 1. Adsorption Kinetic Curves of a. $\mathrm{N}_{2}$ on ACS, b. $\mathrm{O}_{2}$ on ACS, c. $\mathrm{O}_{2}$ on $\mathrm{CSM}_{120}$, d. $\mathrm{N}_{2}$ on $\mathrm{CSM}_{120}$.

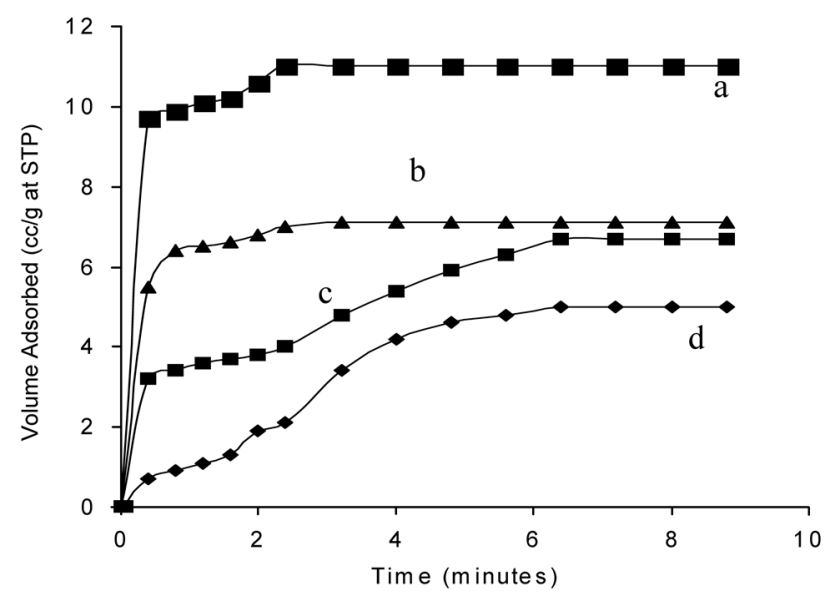

Fig. 2. Adsorption Kinetic Curves of a. $\mathrm{CO}_{2}$ on $\mathrm{ACS}$, b. $\mathrm{CH}_{4}$ on ACS, c. $\mathrm{CO}_{2}$ on $\mathrm{CSM}_{120}$, d. $\mathrm{CH}_{4}$ on $\mathrm{CSM}_{120}$.

tively. It is observed that the amount of adsorbed gases (cc/ gm at STP) gets reversed with change in methane cracking time, for example the uptake ratio for $\mathrm{O}_{2}: \mathrm{N}_{2}$ adsorption for original ACS changes from $0.47: 1.00$ to 3.00:1.00 for a period of 150 minutes of methane cracking. For $\mathrm{CO}_{2}-\mathrm{CH}_{4}$ pair of gases the selectivity ratio for $\mathrm{CO}_{2}: \mathrm{CH}_{4}$ changes from $1.42: 1.00$ to $3.50: 1.00$ for the same duration of methane cracking. It is also interesting to note from Figs. $1 \& 2$ and Table 2 that methane cracking shows improvement in selectivity for separation process for the aforementioned pair of gases, however the process leads to a reduction in volume uptake for $\mathrm{O}_{2}-\mathrm{N}_{2}$ as well as $\mathrm{CO}_{2}-\mathrm{CH}_{4}$. All it appears in simpler terms is that with an increase in cracking time, methane cracked ACS shows a molecular sieving behavior for separation process with a significant loss in adsorption capacity.

Literature on MSC suggests that tailoring of pore mouth in porous carbons is a difficult task in preparation of MSC. This is because during cracking of hydrocarbon the whole process has to be carefully controlled so that adsorption capacity is not diminished significantly [4]. The reduction in adsorption equilibrium experiments for all gases on methanecracked samples in our experiments may be probably due to the excessive pore filling phenomena. Methane being small molecule (kinetic diameter $3.8 \AA$ ) may penetrate deep into the pores or at pore mouth resulting carbon deposition in the whole length of pores rather in pore entrance. This type of cracking results in the reduction of adsorption capacity.

\subsection{Adsorption kinetics of Nitrogen $\left(\mathrm{N}_{2}\right)$, Oxygen $\left(\mathrm{O}_{2}\right)$, Methane $\left(\mathrm{CH}_{4}\right)$ and Carbon dioxide $\left(\mathrm{CO}_{2}\right)$ on $\mathrm{ACS}$ and ACS subjected to benzene cracking}

The volume uptake results for $\mathrm{O}_{2}-\mathrm{N}_{2}$ and $\mathrm{CO}_{2}-\mathrm{CH}_{4}$ pair of gases on ACS as well as ACS samples exposed to the action of benzene are summarized in Table 3 and the kinetic adsorption curves for sample $\mathrm{CSB}_{90}$ are represented in Fig. 3 \& 4 respectively. Here sample $\mathrm{CSB}_{90}$ has been chosen as a representative sample for which results are discussed. It is observed from Table 3 that uptake ratio on original ACS for $\mathrm{O}_{2}-\mathrm{N}_{2}$ pair of gases is $0.47: 1.00$ which changes gradually with cracking time in such a manner that selectivity is favored for oxygen. The optimum of selectivity is observed for sample $\mathrm{CSB}_{90}$. However, as the benzene cracking time is increased further uptake ratio decreases sharply. This may be due to excessive carbon deposition on the pore mouth as mentioned for methane cracking in section 3.1 leading to pore mouth blocking. For $\mathrm{CO}_{2}-\mathrm{CH}_{4}$ pair of gases an increase in benzene cracking time leads to an increase in $\mathrm{CO}_{2}$ uptake volume. For sample $\mathrm{CSB}_{90}$ the uptake ratio for $\mathrm{CO}_{2}-\mathrm{CH}_{4}$ pair of gases is $8.00: 1.00$ and also the volume uptake is quite significant. The uptake ratio further increases for sample $\mathrm{CSB}_{180}$, but the volume uptake observed was very small due to excessive carbon deposition in the pore mouth. From Table 3 it is evident that selectivity ratio for $\mathrm{O}_{2}: \mathrm{N}_{2}$ changes from 1.08:1.00 to 3.31:1.00 for a change in cracking time from 60 to 90 minutes. Under similar set of conditions for $\mathrm{CO}_{2}-\mathrm{CH}_{4}$ pair of gases the uptake ratio changes from 1.68:

Table 3. Uptake ratio of $\mathrm{O}_{2}-\mathrm{N}_{2}$ and $\mathrm{CO}_{2}-\mathrm{CH}_{4}$ on neat ACS and ACS subjected to benzene cracking for different duration

\begin{tabular}{lccc}
\hline Sample & $\begin{array}{c}\text { Cracking time } \\
\text { (minutes) }\end{array}$ & $\begin{array}{c}\text { Uptake ratio of } \\
\mathrm{O}_{2}: \mathrm{N}_{2} \text { at } \\
60 \text { seconds }\end{array}$ & $\begin{array}{c}\text { Uptake ratio of } \\
\mathrm{CO}_{2}: \mathrm{CH}_{4} \text { at } \\
60 \text { seconds }\end{array}$ \\
\hline $\mathrm{ACS}^{*}$ & 0 & $0.47: 1.00$ & $1.42: 1.00$ \\
$\mathrm{CSB}_{60}$ & 60 & $1.08: 1.00$ & $1.68: 1.00$ \\
$\mathrm{CSB}_{90}$ & 90 & $3.31: 1.00$ & $8.00: 1.00$ \\
$\mathrm{CSB}_{180}$ & 180 & $2.50: 1.00$ & $24.0: 1.00$ \\
\hline
\end{tabular}

(Benzene cracking temperature $725^{\circ} \mathrm{C}$, benzene entrainment $0.40 \times$ $10^{-4} \mathrm{~g} / \mathrm{ml}, \&$ nitrogen flow rate $300 \mathrm{ml} / \mathrm{m}$ )

*ACS prepared by carbonization and activation of polystyrene sulfonate beads at $850^{\circ} \mathrm{C}$ for a duration of twelve hours 


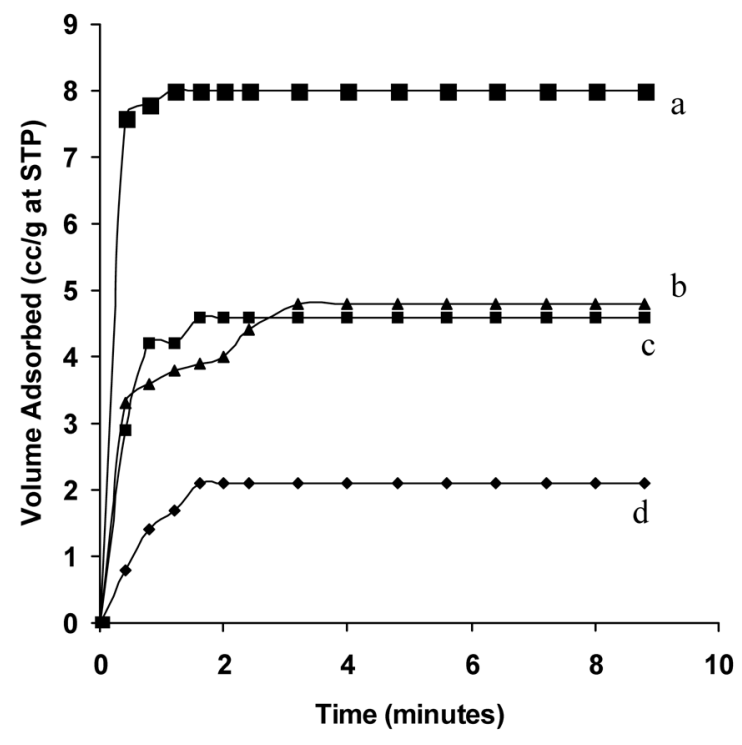

Fig. 3. Adsorption Kinetic Curves of a. $\mathrm{N}_{2}$ on ACS, b. $\mathrm{O}_{2}$ on $\mathrm{ACS}$, c. $\mathrm{O}_{2}$ on $\mathrm{CSB}_{90}$, d. $\mathrm{N}_{2}$ on $\mathrm{CSB}_{90}$.

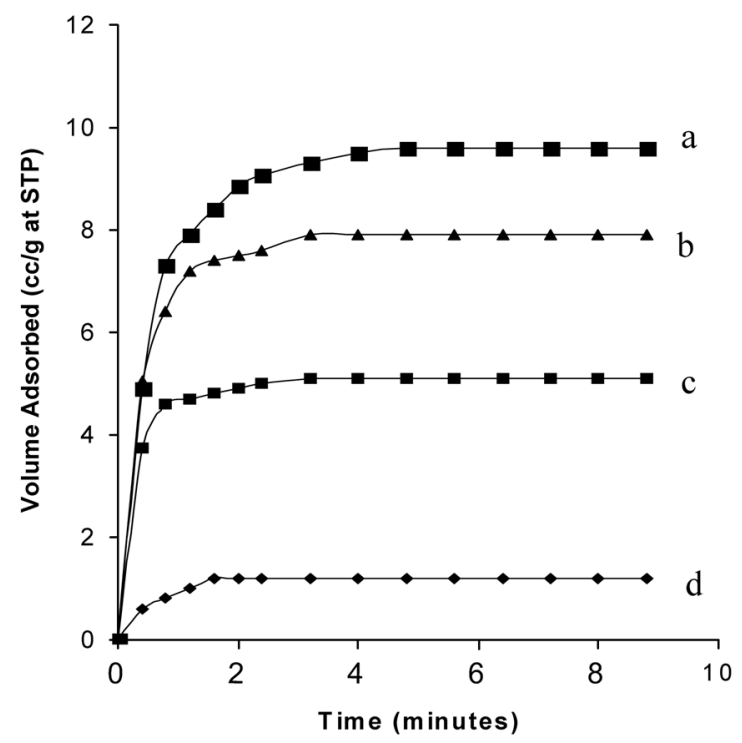

Fig. 4. Adsorption Kinetic Curves of a. $\mathrm{CO}_{2}$ on $\mathrm{CSB}_{90}$, b. $\mathrm{CO}_{2}$ on ACS, c. $\mathrm{CH}_{4}$ on ACS, d. $\mathrm{CH}_{4}$ on $\mathrm{CSB}_{90}$.

1.00 to $8.00: 1.00$. This shows that the change in uptake ratio is substantially high for $\mathrm{CO}_{2}-\mathrm{CH}_{4}$ pair of gases in comparison to $\mathrm{O}_{2}-\mathrm{N}_{2}$ for similar cracking duration. A careful observation on $\mathrm{CO}_{2}$ and $\mathrm{CH}_{4}$ adsorption by $\mathrm{ACS}$ and benzene cracked ACS (see Figure 4) shows that volume uptake for $\mathrm{CO}_{2}$ on benzene cracked is substantially high in comparison to original ACS. However, the same has not been observed for $\mathrm{CO}_{2}$ adsorption on ACS samples exposed to methane. It is realized that selectivity for $\mathrm{CO}_{2}-\mathrm{CH}_{4}$ separation is satisfactory. In general, it is observed that ACS subjected to benzene cracking shows an increase in $\mathrm{CO}_{2}$ volume uptake.

It is well known that $\mathrm{N}_{2}$ at $77 \mathrm{~K}\left(-196^{\circ} \mathrm{C}\right)$ and $\mathrm{CO}_{2}$ at near or ambient temperature is the most common adsorptive gas used to characterize microporous materials [9-10]. However if the pores are very narrow, the entry of $\mathrm{N}_{2}$ molecules at $-196^{\circ} \mathrm{C}(77 \mathrm{~K})$ may be kinetically restricted into the narrowest pores [10]. In this case $\mathrm{CO}_{2}$ adsorption at ambient temperature has been reported a better method for characterization due to higher temperature of adsorption, which would facilitate the entry into narrowest pores. In view of the facts as stated above, the high uptake volume on benzene cracked ACS in our experiments may be due to the presence of ultramicropores which are easily accessible to $\mathrm{CO}_{2}$ at ambient temperature [10]. This finding strongly supports the presence of ultramicropores in benzene cracked ACS. The critical dimensions for $\mathrm{CO}_{2}$ and $\mathrm{N}_{2}$ are similar $\left(\mathrm{N}_{2}-3.64 \AA, \mathrm{CO}_{2}-3.30\right.$ $\AA$ ), hence $\mathrm{CO}_{2}$ may be able to enter into narrowest micropores due to kinetic effect [5]. This possibly is also a reason for benzene cracked ACS to show better separation performance for $\mathrm{CO}_{2}-\mathrm{CH}_{4}$ pair of gases in comparison to $\mathrm{O}_{2}-\mathrm{N}_{2}$ pair of gases. This fact is also supported from the results as shown in Table 1. It is observed that both surface area and micropore volume is substantially low for MSC than that measured for original base material ACS. The pore aperture in MSC being very small, the diffusional resistance against $\mathrm{N}_{2}$ molecules at $-196^{\circ} \mathrm{C}$ is so strong that only a limited amount of nitrogen can penetrate over the given period of time resulting in a bias micropore volume as well as surface area [10]. The vanishing of micropores and conversion of bigger pores in mesopores may be a reason for lower surface area realized for benzene cracked ACS samples. It appears that hydrocarbon cracking on ACS has resulted in overall narrowing of porous structure of ACS. During cracking process some pores have been totally blocked, some partially blocked to critical dimensions of molecules like $\mathrm{CO}_{2}$ and $\mathrm{N}_{2}$. It indicates that benzene cracked ACS has attained molecular sieving character for separation of $\mathrm{O}_{2}-\mathrm{N}_{2}$ and $\mathrm{CO}_{2}-\mathrm{CH}_{4}$ pair of gases.

\subsection{Inversion in selectivity}

As discussed in section 3.1, the kinetic adsorption study for $\mathrm{O}_{2}$ and $\mathrm{N}_{2}$ reveals that ACS containing wider pores show higher adsorption of $\mathrm{N}_{2}$ than that of $\mathrm{O}_{2}$. However, reverse is the case for methane $\&$ benzene cracked ACS. This difference in selectivity could be explained on the basis of difference in mode of adsorption/separation. In case of ACS adsorption is primarily governed by the preferential interaction of molecules on the adsorbent. Here it appears that diffusion into the wider pores is governed by molecular diffusion and adsorption strongly depends on adsorbateadsorbent interaction. Thus the higher adsorption of $\mathrm{N}_{2}$ than that of $\mathrm{O}_{2}$ may be due to higher volume uptake of $\mathrm{N}_{2}$ in wider pores which may be attributed due to larger molecular size of $\mathrm{N}_{2}$ than that of $\mathrm{O}_{2}$. The molecular dimensions for $\mathrm{O}_{2}$ $\& \mathrm{~N}_{2}$ are $3.46 \AA \& 3.64 \AA$ respectively [5]. After carbon 
deposition, the selectivity turns in favor of $\mathrm{O}_{2}$, the reason for the same may be explained in terms of kinetic separation and knudsen diffusion into the pores where the separation depends upon the upon the kinetics of diffusion. Table 1 shows that the presence of mesopores (20-500 $\AA$ ) is substantially high in ACS obtained after the action of benzene cracking. It is cited in the literature that Knudsen diffusion plays a major role in this particular region. Knudsen diffusion occurs in porous media when mean free path of gaseous adsorbent is relatively longer as compared to the pore size leading to frequent collision of gaseous molecules with the pore wall [11].

At high temperature methane/benzene pyrolysis results in carbon deposition on pore mouths of ACS. A controlled quantity of pyrolysed carbon deposited on the pore mouth/ entrance narrows the aperture of ACS. When the pore diameter is reduced to the order of molecular size, it starts to exert a diffusional resistance. As more carbon is deposited at the pore mouths, the pore entrance is narrowed down further to the critical dimensions of the separating molecules enabling kinetic separation due to difference in diffusion rates of separating gases. $\mathrm{O}_{2}$ being smaller in size, diffuses faster into the pores as compared to $\mathrm{N}_{2}$, gets adsorbed and $\mathrm{N}_{2}$ enriched stream is obtained at the outlet, allowing a better selectivity for oxygen and inversion in selectivity may be due to change in transport phenomenon of adsorbate into the pores.

\section{Conclusions}

MSC found to be effective for separation of $\mathrm{O}_{2}-\mathrm{N}_{2}$ and $\mathrm{CO}_{2}-\mathrm{CH}_{4}$ pair of gases has been prepared through CVD of methane and benzene on polystyrene sulfonate derived ACS. It is observed that cracking of methane on ACS resulted in MSC showing good selectivity for $\mathrm{O}_{2}-\mathrm{N}_{2}$ and $\mathrm{CO}_{2}-\mathrm{CH}_{4}$ separation with a loss in adsorption capacity which may be attributed due to excessive carbon deposition in whole length of the pores rather than on pore entrance. MSC with acceptable adsorption capacity for $\mathrm{CO}_{2}$ and showing good selectivity for $\mathrm{O}_{2}-\mathrm{N}_{2}$ \& $\mathrm{CO}_{2}-\mathrm{CH}_{4}$ separation was obtained by benzene cracking on ACS.

\section{Acknowledgements}

The authors are thankful to Dr. K. U. Bhaskar Rao, Director, DMSRDE -Kanpur \& Anurag Srivastava, Scientist "E", DMSRDE -Kanpur for their kind support and encouragement during the course of this work.

\section{References}

[1] Vyas, S. N.; Patwardhan, S. R.; Vijaylakshmi, S. J. Colloid and Interface Science 1994, 168, 275.

[2] Arriagada, R.; Bello, G; Garcia, R.; Reinso, F. R.; Esribano, A. S. Microporous and Mesoporous Materials 2005, $81,161$.

[3] Halat, M. J.; Kedzior, K. Carbon 2005, 43, 944.

[4] David, E.; Talaie, A.; Stanciu, V.; Nicolae, A. C. J. Materials Processing Technology 2004, 157-158, 290.

[5] Vyas, S. N.; Patwardhan, S. N.; Gangadhar, B. Carbon 1992, 30(4), 605.

[6] Vyas, S. N.; Patwardhan, R.; Natraj, H. B. J. Chem. Soc. Faraday Tran. 1990, 86(20), 3455.

[7] Sircar, S.; Golden, T. C.; Rao, M. B. Carbon 1996, 34(1), 1.

[8] Rodil, S. V.; Avarrete, R. N.; Denoyel, R.; Albiniak, A.; Paredes, J. I.; Alonso, A. N.; Tascon, J. M. D. Micro Porous and Mesoporous Materials, 2005, 77, 109

[9] Garrido, J.; Linaressolano, A.; Martin-Martinez, J. M.; Molina-Sabio, M.; Rodriglez-Reinso, F.; Torregrosa, R. Langmuir 1987, 3, 76.

[10] Lozano-Castello, D.; Cazorla-Amorous, D.; Lanares-Solano, A. Carbon 2004, 1233.

[11] Arnold, E. "Porosity in carbon", ed. Patrick, W. John St. Edmundsbury press, London, 1995. 